\title{
Los Ríos Occidentales de la HisPania Romana EN LAS FUENTES CLÁSICAS. UNA APROXIMACIÓN
}

\author{
Manuel J. Parodi Álvarez \\ Universidad de Cádiz
}

Recibido: 01/09/2013

Revisado: 17/01/2014
Aceptado: $12 / 02 / 2014$

Publicado: 20/05/2014

\section{RESUMEN}

Presentamos en los siguientes párrafos una aproximación a la información ofrecida por algunas de las principales fuentes clásicas acerca del fenómeno de la navegación por algunos de los ríos occidentales de la Hispania romana, con una especial atención a los cursos mayores de la región, caso del Guadiana, el Tajo o el Duero en época romana

\section{Palabras Clave}

Península Ibérica; Hispania Romana; Ríos; Autores clásicos; Navegación fluvial.

\section{ABSTRAC}

In the following paragraphs we present an approach to the information provided by some of the main classical sources on the phenomenon of sailing through some of the western rivers of Roman Hispania, with special attention to the mayor rivers in the region, it is the Guadiana, the Tajo and the Duero in Roman times.

\section{KEYWORDS}

Iberian Peninsula; Roman Hispania; Rivers; Ancient historians; River sailing.

sidiadir@hotmail.com 
No son precisamente pocas las menciones, relativas a época romana, que de los cursos fluviales de la Península Ibérica que desaguan al Océano Atlántico podemos encontrar en las fuentes literarias clásicas; entre los autores considerados puede ser Estrabón (el tratadista de época augústea) quien con mayor detenimiento aborde el particular, pero no habrán de ser los datos ofrecidos por el amasiense los únicos que interesen de cara a la consideración de la navegación interior por los ríos del Occidente Peninsular Hispánico en tiempos romanos.

El eje físico formado por los hodiernos ríos Tinto y Odiel aparece ya mencionado por el citado Estrabón, quien se refiere al mismo cuando hace mención de los "esteros de Onoba": el amasiense (Geogr., III.2.5, 143) menciona explícitamente esteros como los de Nabrissa, Onoba y Ossonoba, pero el mismo Estrabón (III.1.9, 140) un poco antes de la cita anterior realiza asimismo una mención general -una somera panorámica- de los estuarios y esteros situados al Oeste de las bocas del Baetis, una mención en la que se encontrarían incluidos (pese a no ser específicamente nombrados) los esteros de la ría onubense.

Al mismo tiempo el amasiense hace mención del río Iber (o Hiberus, a no confundir con el homónimo que las fuentes sitúan en el Noreste peninsular y que encontraría su moderna equivalencia en el río Ebro); este río Iber suroccidental contaría en su curso con una laguna, la "Palus Ereba" o laguna del Erebo (lo que es decir, del Infierno), un equivalente (físico, geográfico...) de la mítica laguna Estigia (uno de los hipotéticos emplazamientos de la misma), el emplazamiento de la cual Rufo Festo Avieno (en su Ora Maritima, versos 241-253) sitúa precisamente en la costa onubense, especificando que dicha laguna infernal estaría atravesada por un río "Iber" -que no se correspondería con el moderno Ebro- el cual habría dado su nombre a "Iberia" (o habría tenido su parte en dicha denominación, como el "Iber" del Noreste -recordemos que "Iber" ya es "río", en sí), esto es, a la región bañada por sus aguas -teóricamente, la Andalucía Occidental y más de forma más específica la actual Huelva costera); el mencionado Iber onubense sufriría cambios de nivel con independencia de lluvias y deshielos, unos cambios de nivel que serían puestos en relación por el antedicho Estrabón con los efectos de los vientos del Norte (Estrabón, Geographiká III.5.9, 175); el viento del Norte -en un diferente contexto- es mencionado por Herodoto
II.20 (quien lo toma de Tales de Mileto) entre las causas materiales de los desbordamientos del africano río Nilo.

No insistiremos en la relación de ese río "Iber" con las costas andaluzas y su posible identificación precisamente con el eje Tinto-Odiel y la ría de Huelva, al ser cuestión sobradamente señalada y debatida con anterioridad; así, A. Schulten (1963, 63-ss.), identifica directamente el Hiberus (o Iber) de Huelva con el Luxia de Mela y Plinio, el moderno río Tinto (sosteniendo además que el estuario y curso del Tinto podría haber sido navegable en la Antigüedad hasta Ilipula (Niebla); igualmente trata sobre este particular A. García Bellido, (1944, 532-ss.); cfr. asimismo la edición de la Geografía (libros III-IV) de Estrabón en la Biblioteca Clásica Gredos (Madrid 1992, pg. 130, nota 317): los editores señalan -respecto al fenómeno del desbordamiento del río Iber como consecuencia de los aportes de la Laguna del Infierno (aportes a su vez provocados por los vientos del Septentrión, de acuerdo con lo señalado por la fuente) citado por el amasiense (en su Geografía, III.5.9)- que tal cita geográfica estraboniana “...no puede referirse al Ebro pero sí al Hiberus localizado en la zona de Huelva, que atravesaba la Palus Ereba citada por Avieno, Or. Mar. 243".

Por lo que respecta al Anas, su mención aparece tanto en Estrabón (Geografía, III.1.6-7, 9; III.2.3) como en Mela (Chorografía II.87; III.6.) y Plinio (Naturalis Historia, III.6-8; IV.116-117.); la navegabilidad de este curso (si bien en menores proporciones que en el caso del Baetis) aparece ya refrendada por las fuentes históricas, especialmente por el amasiense; de este modo Estrabón especifica que el Anas es navegable pero durante menos trecho que el Guadalquivir y por embarcaciones de menor porte que en el caso bético, al tiempo que rinde cuenta de la presencia de una doble desembocadura del Guadiana (Geografía III.1.9 y III.2.3). Por lo demás, Mela no se detiene a considerar de manera específica su posible navegabilidad, mientras Cayo Plinio sí se ocupa por su parte en mencionar la existencia de unas lagunas en su curso (N.H. III.6.).

De esta forma es posible considerar cómo el Anas, un curso fluvial que formaba parte de la cosmografía mítica de la Antigüedad, que se muestra velado por las brumas de Tartessos y que -por un tiempo- aparecería como un límite entre los primeros territorios romanos en el Sur de Iberia y las aún bárbaras tierras del Oeste lusitano y el Centro 
peninsular celta, un accidente geográfico que tanto en sus tramos inferiores y costeros (como apunta Estrabón al describir la doble desembocadura del río) como en sus tramos medio y superior (y en este caso es Plinio quien habla de las lagunas del interior, mientras el antedicho amasiense se detiene a considerar la existencia de montañas con minas en la ribera norte del Guadiana, unas montañas mineras que alcanzarían hasta el Tagus, a la vez que menciona a la árida Baeturia que bordea al Anas) resulta relativamente bien conocido por los autores antiguos, pese a lo cual las descripciones que dichas fuentes llevan a cabo acerca de dicho curso fluvial no suelen ser demasiado detalladas, ni extensas, si bien destacan su condición de curso susceptible de ser navegable (si bien con limitaciones), la aridez de las tierras que lo envolvían y la potencialidad minera de la región que se extendía más al Norte, entre los cursos del Anas y el Tajo (Parodi, 2003b).

El asunto de la navegación del Anas sigue siendo objeto de controversias entre los estudiosos contemporáneos; así, si bien el hecho físico de la navegación por el Guadiana no es puesto en duda, sí es causa de discusión el volumen, importancia y continuidad de la misma. El obstáculo principal para la navegabilidad del Anas, aparte del caudal y los factores de estacionalidad que a éste pueden afectar (Garcia, 1982, 5-ss.), junto a vados y zonas de escasa profundidad (Rodríguez Díaz, 1994, 107-ss.), viene a ser el salto de agua de "Pulo do Lobo" (de unos 15 $\mathrm{m}$ de altura), a la altura de la localidad portuguesa de Serpa. Este accidente natural supone un punto de forzosa y necesaria inflexión en el empleo del Guadiana como vía fluvial, puesto que la continuidad horizontal del río (su unidad de pendiente) se ve rota a causa de este desnivel. Este obstáculo marca -como es de entender- el ritmo de la navegación por el río, de modo que ciertos investigadores han considerado que el salto de Pulo do Lobo pudiera ser el límite absoluto para la navegabilidad del Anas (da Silva Lopes, 1841/1988, 23).

En lo que sí parecen coincidir no pocos autores de los que han abordado el tema del comercio por el Guadiana es en la hipótesis de la progresiva reducción de la superficie navegable del río; de esta manera, si bien en época romana habría sido posible (gracias al sistema de navegación por tramos del río -esto es, de navegación discontinua) alcanzar Mérida desde la desembocadura, en el siglo XIII no habría sido factible navegar más allá de Mértola (Garcia, 1982, 16-ss.; id., 1996, 60), ciudad que continuaría siendo el "gran" puerto fluvial interior del Anas hasta el siglo XIX (da Silva Lopes, loc. cit.). Así, la navegación por el Guadiana parece confirmarse como un ejemplo notorio de actividad desarrollada (adaptándose a las circunstancias y las condiciones del medio fluvial en cuestión) de forma intermitente en el espacio, de modo que, como sostiene J.C. Garcia (1982, passim), sí sería posible surcar el río entre las poblaciones de Mérida y Badajoz, así como entre la desembocadura y MértolaMyrtilis, pero quizá no entre Myrtilis y Badajoz.

Resulta oportuno observar, dada la relevancia de la zona en cuestión y del río que la articula, cómo en el ámbito del Anas se encuentran varias ciudades romanas de notable peso y papel administrativo, entre las que hemos de contar una de las capitales provinciales de Hispania, Emerita Augusta, y una capital conventual, Beja (Pax Augusta). Sabemos que Myrtilis sirvó como puerto fluvial en el Anas; a este respecto, cfr. Gómez y Lopes, 2009, 15-ss., quienes exponen la potencialidad del puerto fluvial de la Mértola romana, y de manera muy acertada señalan la relevancia de este punto en el valle del Guadiana como eje articulador de rutas fluviales -especialmente río abajo del salto de agua de Pulo do Lobo- y terrestres en el ámbito del Guadiana antiguo, poniendo en relación directa a Myrtilis y a Beja, siendo la primera el puerto fluvial de la segunda, lo que viene a incidir en la idea (expuesta por nosotros en otros lugares: cfr. Parodi, 2001, passim) de que allá donde es posible, Roma tratará de emplear las vías fluviales como medios y mecanismos de comunicación y transporte).

Sabemos que Myrtilis habría servido como puerto de Beja, tal y como sostienen algunos estudiosos (Garcia, 1982, 12-ss.; Spaar, 1981, 225-ss.; Gómez y Lopes, 2009, 15-ss.; de otra parte, Spaar, 1981, 230, sostiene que en Mértola habría estado -a más de $60 \mathrm{~km}$ al interior- el primer paso transversal fijo sobre el Guadiana antiguo, siendo cuando menos hasta allí navegable el río para embarcaciones de dimensiones no reducidas, algo -esto último- en lo que inciden Gómez y Lopes, 2009, 19, quienes señalan que las estructuras por ellos identificadas con una torre tardorromana no pudieron estar adscritas a -ni relacionadas con- la estructura de un puente, de un paso fijo época romana de sobre el río Anas a su paso por Mértola, contraviniendo de este modo lo señalado por Spaar -loc. cit), de forma que la combinación de rutas fluviales y terrestres garantizase la comunicación entre Beja y el mar (Ro- 
dríguez, 1995, 111-ss.), de manera que -por ejemplo- el transporte se realizase por el río allá donde fuese posible, empleándose la ruta terrestre como alternativa (más cara que la comunicación por vía acuática pero necesaria, cuando no imprescindible en determinados momentos y lugares) en aquellos tramos del curso fluvial en cuestión -en este caso el Guadiana romano- en los que la navegación no resultase posible (García, 1996, 5-ss.; Parodi, 2001, passim).

Además, hemos de observar cómo las capitales y ciudades (de distinto rango) cuya existencia conocemos en la región del Anas, habrían de mirar hacia el río para su mejor servicio y abastecimiento, un río que podría servir para el transporte de materiales como los que en pleno siglo V de la Era habrían sido empleados para la reconstrucción de la metrópolis emeritense tras el azote de los suevos (vid. sobre el particular Mateos, 1995, 125-ss.). Significativa resulta la aparente ausencia de obras de canalización en el río, unas obras que hubieran podido servir para asegurar y garantizar la navegación por el mismo, obras que sí encontramos en otros cauces peninsulares (caso del Baetis), o bien obras que podrían haber simplemente señalado con claridad la ubicación del puerto fluvial en el río Anas a la altura de Mérida (como sí resulta suceder en el caso de la ciudad portuaria de Myrtilis -cfr. Gómez y Lopes, 2009, 15-ss.); sí contamos, sin embargo, con la presencia de un puente -aún en el siglo $\mathrm{V}$ d.C.- en Emerita, algo significativo si pensamos que en fecha tan posterior como el reinado de Alfonso XI de Castilla (siglo XIV) se contaría (siquiera de forma puntual, de cara a dotar de infraestructura a una expedición militar del citado soberano castellano) con un puente de barcas sobre el Guadiana (puente de barcas que, dado su carácter no permite mayores aseveraciones acerca de su hipotético papel en relación con la navegación continuada por el río; cfr. Garcia, 1996, 63-64); contamos al mismo tiempo con noticias documentales sobre la existencia de navegación visigoda por el Anas hasta Mérida (Garcia, 1982, 4), algo que parecería confirmarse por la presencia bizantina en la antigua capital emeritense (Cerrillo, 1995, 30-ss.) en la sexta centuria de la Era (un puente, el emeritense, que en sí mismo no tiene por qué significar un límite ni un obstáculo para la navegación por el río, pero cuya presencia viene a señalar una relación notable -de interacción, estabilidad y continuidad- entre el viario terrestre y el río, un viario terrestre estrechamente relacio- nado con los cursos acuáticos de la zona; cfr. Rodríguez, 1995, 116-ss.)

Otros cursos fluviales de la misma vertiente atlántica occidental peninsular cuentan con un menor predicamento -aun- en las fuentes históricas; de esta manera, podría reconocerse al estuario y desembocadura del río Sado en uno de los esteros de la costa que se despliega entre el Promontorio Sagrado y la boca del Tajo, un estuario y desembocadura que habría resultado navegable de acuerdo con Estrabón hasta Salacia (la actual Alcácer do Sal), lo que representa una distancia de unos cuarenta kilómetros al interior. Si bien se trata de una bahía que se va estrechando hacia el interior, sometida a la acción de las mareas (que alcanzan hasta Alcácer do Sal hoy día), lo que posibilitaba grandemente la navegación por sus aguas (Estrabón, Geografía III.3.1); este carácter y naturaleza de bahía y refugio útil y seguro para la navegación costera habría sido ya recogido por Avieno (O.M., 187, 199) en su Periplo.; sobre el Sado se pronuncia igualmente Ptolomeo: Schulten identifica el río Kallipus de Ptolomeo (II.5.2) con el moderno Sado (Schulten, 1963, pp. 68-69); no mucho más encontraremos en las fuentes acerca del río Sado, excepción hecha de la mención que Avieno hace en su Ora Maritima sobre la bahía sadina y su utilidad como fondeadero y refugio seguro para la navegación de cabotaje romana.

Del mismo modo, otros cursos de menor entidad del ámbito atlántico portugués se encuentran igualmente reflejados en los textos antiguos a través -siquiera- de alguna que otra escueta referencia; así sucede con los Mundas-Mondego y Vacua-Vouga; el Mundas (o Munda) aparece citado bajo tal denominación por Estrabón(III.3.4), Pomponio Mela (III.8) y Plinio el Viejo (N.H. IV.115 -Aeminius en IV.113), quien lo recoge igualmente bajo el nombre de Aeminius; de entre ellos sólo el amasiense se detiene a considerar la navegabilidad del río Mondego, señalando además que tal actividad es factible sólo a lo largo de un corto tramo. De otra parte en lo que atañe al curso del Vouga, éste aparece en los textos de los citados Estrabón (Geog. III.3.4) y Plinio (N.H., IV.113 -bajo la denominación de $V a$ gia) así como de Ptolomeo (II.5.3), si bien sólo en la Geografía del de Amasia se recogen algunas de las -si breves- posibilidades que el citado Vouga ofrecía de cara a su navegación (que hemos de entender se realizaría mediante embarcaciones de reducidas dimensiones, quizá con las monóxilas, esto es, em- 
barcaciones construidas a partir de un solo tronco arbóreo vaciado hasta conseguir un casco susceptible de ser empleado como medio de navegación).

Algo diferentes (en cuanto a la información de que disponemos sobre los mismos) resultarán los casos de los dos cursos fluviales mayores de esta fachada occidental peninsular, esto es, los ríos Tajo y Duero, a los cuales las fuentes literarias de la Antigüedad prestarán una mayor (y mejor) atención. Por lo que respecta al río Tajo (el Tagus romano), Estrabón señala (lo que no aporta excesivo detalle sobre el mismo) el emplazamiento de su desembocadura en el litoral occidental de Iberia (Geog. III.1.6) así como su origen en las tierras interiores de la Celtiberia (III.4.12); A. Schulten (1963, pg. 74) sostiene, en cambio, que el Tagus al que se refiere el grecolatino Estrabón en este pasaje no sería el moderno Tajo, sino su afluente el Tajuña o Tagonius, mencionado bajo esta última denominación por Plutarco (Sert. 17), pero que aparece bajo el nombre de Tagus (o Tagum) en Marcial (IV.55; VII.88; X.65; XII.3.3); la diferencia radica en el origen de uno y otro curso, puesto que Estrabón y Marcial sitúan el nacimiento del Tagus al que se refieren en la Celtiberia, lo que sólo se cumpliría en el caso del río Tajuña.

El texto del amasiense Estrabón en que se mencionan las condiciones de la desembocadura del $T a$ gus no resulta excesivamente prolijo, si bien podemos señalar que la anchura de la misma -según este autor- habría de ser de unos veinte estadios (i.e., aproximadamente unos 3'5 kilómetros), formándose en la misma dos estuarios a consecuencia de la acción de las mareas atlánticas (Geog., III.3.1.); de acuerdo con el muy consultado texto estraboniano (vid. A. Schulten, 1963, pp. 70-ss.; A. García Bellido, 1944, pp. 515-516); este doble estuario de la desembocadura del río Tajo resultaría susceptible de sustentar el hecho de la navegación marítima, y podrían navegarlo embarcaciones con una capacidad de carga de hasta diez mil ánforas (o lo que es lo mismo, naves marinas, buques mercantes de alta mar); igualmente se pone en conocimiento del lector de que el océano llegaba incluso a inundar los campos del curso bajo del referido río en una distancia de más de ciento cincuenta estadios (unos $30 \mathrm{Km}$. al interior).

En lo que atañe a los límites de la navegación por los mencionados estuario y curso inferior del río Tajo en época romana, éstos son establecidos para embarcaciones marítimas en la isla de Moron por el amasiense (esto es, unos quinientos estadios río adentro), resultando factible surcar el río aguas arriba de la referida isla merced al empleo de embarcaciones fluviales, capaces de navegar las aguas interiores; igualmente nos llegan de mano de Estrabón las noticias de las funciones desempeñadas por la dicha isla (y ciudad) de Moron -la actual localidad portuguesa de Almourol, en la confluencia del Tajo con uno de sus afluentes principales por la ribera derecha, el río Zêzere (vid. Kalb y Höck, 1988, pp. 189-ss.; cfr. igualmente -para la existencia de un fortín militar de fines de la República romana en Mourâo- do Paço y Baçâo Leal, 1968, pp. 1-ss.; para las “diez mil ánforas”, cfr. Rougé, 1966, pp. 68 y 79), como base de operaciones por el cónsul romano Décimo Junio Bruto Calaicus (que fuera gobernador de la Vlterior) en sus campañas lusitanas (en el siglo II a.C.).

Este mismo Bruto Galaico (que ganó su cognomen como consecuencia de sus campañas militares en el Occidente y el Noroeste hispano, y de su victoria sobre los Callaeci) habría fortificado igualmente la ciudad de Olisipo, en este contexto de la desembocadura del río Tagus con la intención de hacer de dicho núcleo no sólo un más sólido eje vertebrador del territorio, sino de convertir a dicha población en el vértice y la punta de lanza (por así decirlo) de la penetración romana en el territorio (desde la desembocadura del Tajo), así como (y siempre de acuerdo con lo vertido por el tan citado Estrabón) para asegurar asimismo la navegación -militar y comercial- sobrr las aguas del estuario del río y hacia el interior de sus tierras, de manera que pudieran quedar firmemente consolidados los canales de abastecimiento del ejército romano en la región y con ello, la presencia romana en las tierras del remoto (desde la perspectiva de la Roma del siglo II a.C.) Occidente de la Península de Iberia (Estr., III.3.1); sobre las campañas de Décimo Junio Bruto, cónsul en 138 a.C. y pacificador de la Lusitania y las novelescas circunstancias de su cruce del mítico río del Olvido (el Letheo-Limia), véase. Livio A.V.C., LV; de esta manera volvemos a encontrar en el bajo Tajo unas premisas estratégicas y económicas de ocupación del territorio por parte de Roma similares a las que pueden considerarse en otros contextos peninsulares ibéricos, como en el caso del río y valle del Ebro.

Otros autores clásicos que hacen mención del Tajo serán (de acuerdo con Schulten), Silio Itálico (I.151), quien hace referencia a las notables dimen- 
siones del estuario taguino, Cayo Salustio Crispo (Hist. I.115), quien hace referencia a las crecidas del río (un asunto del que ya se ocupara el amasiense Estrabón), o el poeta Virgilio (Catal. IX. 11.52), quien tilda al río de "rapidus" (A. Schulten, op.cit., pp. 72-73; para otras referencias a autores clásicos que tratan y/o mencionan al Tajo, vid. Schulten, loc. cit.). Por su parte Pomponio Mela (natural del meridión hispano, como es sabido), menciona cuestiones tales como la producción aurífera y de piedras preciosas del río Tagus, si bien sin entrar en ulteriores y mayores precisiones (Chor., III.8.), mientras Plinio el Viejo no realiza tampoco una mención específica de la posible navegabilidad del antiguo Tajo, aunque sí se detiene a considerar el mito de las yeguas lusitanas preñadas por el viento Céfiro -o Favonio- en los campos taguinos de Olisipo, de cuyos embarazos llegaban a obtenerse unos potros extraordinariamente veloces, unos animales de salud inconsistente (como hijos del viento que eran...) y condenados por su propia naturaleza y esencia a una vida singularmente breve (N.H. III.19, 25 -sobre los toletani, que estaban sobre el río $T a$ gus; IV.115-116; VIII. 166 -para las yeguas olisiponenses y el dios-viento Céfiro; acerca del papel del aire como elemento fecundador, como elemento generador que "insufla" la vida -en los hornos, por ejemplo- vid. Chic, 1997, passim; igualmente, cfr. Parodi, 2004, 357-ss.).

Schulten recoge la existencia de tres puentes sobre el Tajo en la Antigüedad, esto es, el que se atribuye a Augusto en Toledo, el de Trajano en Alcántara y el de Alconétar, que permitía a la calzada Emerita-Salmantica salvar el paso sobre el curso del Tagus (sobre el puente de Toledo, Chron. Min. II.380; sobre el de Alcántara, CIL II.759; cfr. A. Schulten, op. cit., pg. 73.). El famoso puente de Alcántara, situado en un cañón del río Tajo, dispone de seis arcos; la luz de los arcos centrales -los mayores- alcanza los 28 metros, mientras en los arcos menores está próxima a los $18 \mathrm{~m}$; esto viene a demostrar que la estructura del puente no habría llegado a representar en modo alguno un impedimento para la navegación fluvial (algo apreciable con la mera observación del citado puente); además sabemos de distintas líneas de navegación que en épocas moderna y contemporánea se habrían establecido en el Tajo, unas líneas que habrían funcionado por el río -incluso en el caso de embarcaciones a vapor en el siglo XIX- sin dificultades mayores. Ello nos lleva a replantearnos una vez más la hipotética (y nunca general) dificultad que los puentes de piedra podrían llegar a representar para la navegación por los cursos fluviales ibéricos (en algunos casos obvia, en otros irrelevante cuando no inexistente); en el caso del puente de Alconétar, trasladado hoy de emplazamiento (se encontraba originalmente en la confluencia del Tajo con su afluente el río Almonte) y objeto de diversas destrucciones (y refacciones) a lo largo del tiempo, sus arcos habrían contado (al menos lo mayores de éstos) con una luz de 7’10 m., una altura que debería haber resultado más que suficiente de cara a permitir el paso de embarcaciones fluviales bajo los arcos mayores (para el comportamiento de la navegación en cursos acuáticos menores fuera del contexto de la Península Ibérica, vid. Eckoldt, 1984).

Otro puente digno de consideración es el que se encuentra en Emerita Augusta, sobre el río Guadiana; este notable paso firme se extiende a lo largo de $800 \mathrm{~m}$. y cuenta con una altura de doce metros, por lo que tampoco habría debido constituir un mayor obstáculo para la navegación por el curso del Anas; pese a sus diferentes refacciones a lo largo de la Historia (intervenciones provocadas por lo continuado de su uso así como por la sucesión de diversos avatares tan lejanos entre sí en el tiempo como el ataque de los suevos a la capital emeritense del año 429 de nuestra Era, o la destrucción parcial sufrida asimismo por el citado puente en el curso de la Guerra de Independencia Española, a principios del siglo XIX -nótese que estamos hablando de hechos históricos alejados entre sí casi milenio y medio, avatares que en ambos casos redundaron en perjuicio de esta estructura histórica), es indudable el carácter y origen romano del puente, como sucede igualmente en el caso de otro puente también situado en Mérida, en este caso sobre el arroyo Albarregas (afluente a su vez del Anas), un paso firme de menor entidad que el gran puente situado sobre el río Guadiana (vid. al respecto A.A.V.V., 1980, pp. 14-ss.).

En relación con el paso firme de Mérida sobre el Anas se nos informa de la existencia de un portus fluvial romano en sus proximidades; debería tratarse quizá del puerto de Emerita, que junto con el puente formaría la segunda cara de la moneda del eje de comunicaciones (fluvial y terrestre) emeritense; sobre el puente romano de Emerita Augusta, vid. igualmente J.M A $^{\mathrm{a}}$ Álvarez Martínez (1983, pp. 5-ss.), quien se pronuncia en contra de la navegabilidad del Anas a su paso por Mérida, si 
bien sí recoge testimonio de la existencia de diversas obras destinadas a mejorar las condiciones de canalización y caudal del río a dicha altura (como “...los restos de un poderoso tajamar o aleta de encauzamiento que hubo de realizarse para preservar al puente de la furiosa embestida de las aguas" o el dique de la Alcazaba, el cual (siempre de acuerdo con el autor) "...no puede ser considerado más que un muro de protección de la ciudad contra el río..." (Álvarez, op. cit., pg. 11).

La presencia de algunos pasos fijos sobre el Tagus en época romana, caso del ya mencionado puente de Alcántara (en la actual provincia de Cáceres) no habría de suponer siempre un inconveniente -ni una mayor dificultad-para la continuidad de los desplazamientos por vía fluvial, puesto que estos pasos firmes -en el caso de ser establecidos- debían dar satisfacción a unas determinadas necesidades de carácter tanto económico como estratégico, al mismo tiempo que debían verse asimismo sujetos en su fábrica a diversos condicionantes de naturaleza física y geográfica; así, de esta forma y en el caso de ser edificados, estos pasos firmes de piedra serían construidos de modo que -en la medida en que ello resultase posible- no llegasen a resultar un impedimento para el paso y desenvolvimiento (que podemos imaginar fluido) de las pequeñas embarcaciones fluviales que representaban la espina dorsal del tráfico y las comunicaciones por estos cauces interiores peninsulares susceptibles de sustentar dicha navegación sutil; incluso en caso diferente o incluso contrario, un puente de piedra por sí solo no habría de suponer un impedimento (en términos absolutos) para la travesía de su río (contando con que la navegación por este cauce sí resultase factible), sino un punto de inflexión y de transbordo para el tráfico comercial fluvial, de manera que la existencia de dicho paso firme estable podría encontrarse (como en el ejemplo emeritense) en directa relación con la presencia de un portus fluvial en el cual se realizarían las tareas y funciones propias del embarque y desembarco de personas y de mercancías y su oportuna (en su caso) transferencia y transbordo a otras embarcaciones con vistas a dar continuidad al hipotético fenómeno del desplazamiento y transporte por el curso fluvial.

La legislación romana es clara sobre la obligación general de no interrumpir ni entorpecer los cursos de agua; así, el Digesto establece la utilidad pública de los ríos (I.8.4: "flumina paene omnia et portus publica sunt”), y Ulpiano (en XLIII.12.1.3) aclara el sentido de "río público": "fluminum quaedam publica sunt, quaedam non; publicum flumen esse Cassius definit, quod perenne sit (recogido por Chic, 1990, pg. 49, n. 55); en algunos casos, como en el ya mencionado puente de Alcántara, la solución estribaba en elevar la altura de sus luces (aprovechando si acaso era posible las propias condiciones del lugar donde se emplazaba el puente en cuestión), de forma que resultase más fácil y cómodo para las embarcaciones fluviales surcar las aguas del río bajo los arcos de los puentes.

Señala Bonsor (1989, pg. 84) que por "portus" “...se debe entender no sólo los muelles fluviales donde los barcos iban a cargar y descargar sus mercancías, sino probablemente también el pasadizo, la abertura o el canal construido en el dique, es decir, la compuerta misma. Es uno de los significados actuales de la palabra hispana puerto"; por su parte, Chic (1992, pp. 133-ss.) a porta nuevas conclusiones sobre el sentido el término portus: señala -comentando al Digesto (L.16. 59: portus apellatus est conclusus locus, quo importantur merces et inde exportantur) que por "portus" pueden ser entendidos no sólo los muelles y los almacenes (Ponsich, 1979, pg. 68: portus como “...entrepôts, magasins...”) y el resto de las instalaciones portuarias -en el caso que nos ocupa, fluviales) sino también los diques de regulación de los ríos (siguiendo el sentido que daba Bonsor al término); la existencia de estos diques daría forma a lugares donde se haría necesario en algunos casos el transbordo de las mercancías, al tratarse de un lugar cerrado (conclusus locus) a donde llegarían productos (quo importantur merces) y desde el cual -tras el transbordo de los mismos a embarcaciones menores o bien tras su desembarco y posterior embarque- continuaría el tránsito de los mismos (inde exportantur).

Junto a las posibles presas y diques romanos, cabe citar como ejemplo de conclusus locus -en el contexto del Baetis- al así llamado "Vado de las Estacas" de Ilipa Magna (Alcalá del Río), lugar en el que la navegación debía sufrir una inflexión y donde las mercancías transportadas deberían ser desembarcadas para ser -salvado ya el obstáculo del vado- vueltas a embarcar a continuación (Millán, 1989, pp. 28 y 77-78). La existencia de estos portus romanos parece ser confirmada por los topónimos conservados que hacen referencia a los mismos en diversos contextos peninsulares (caso de "Puerto el Barco", en la sevillana localidad de Brenes, o de "El Portal”, en el Guadalete, entre Jerez y El Puerto de 
Santa María), como sostiene G. Chic (1992, pg. 135). Del mismo modo, no pocos testimonios epigráficos conservados señalan la existencia de instalaciones e infraestructuras romanas en el curso de ríos europeos (CIL XV, 107-110; CIL XV, 111). Las infraestructuras romanas no sólo habrían de dejar sus huellas en el caso de la toponimia española: también en otros territorios del Imperio, como Francia e Italia, por ejemplo, se conservan aún en la actualidad topónimos referentes a hitos y lugares sitos en el curso de ríos que fueron navegables en época romana, unos topónimos directamente derivados de los latinos (Grénier, 1960, vol. VI, pg. 475 y n. 3).

Para la representación gráfica de un conjunto de esclusas (una de las acepciones del término "portus") así como para diversos ejemplos medievales (en ámbitos italiano y germano) de obras de canalización (entre ellas los proyectos realizados por Leonardo da Vinci para el Naviglio Grande en el Ticino, Italia) y contención de cursos interiores (así como de canales marítimos, en el caso de los Países Bajos), vid. R.J. Forbes (1965, pp. 56-ss.); igualmente, en un contexto extraeuropeo, P. Briant (1986, pg. 16 y n.10): los textos acadios también designaban como portus ("babu") a estos diques del Tigris, que disponían asimismo de abertura central; sobre este particular (los diques con abertura central, pero en época romana), se pronuncia G. Chic (1990), quien presenta datos sobre la construcción de aggeres o terraplenes para contener las riberas en Egipto (Ulpiano, Dig., XLVII, 11, 10, los llama "chómata") así como en Germania, en el río Nicer-Neckar (siguiendo al militar e historiador de época de Juliano el Apóstata -o el Grande- Amiano Marcelino, XXVIII.2.3, quien explica el procedimiento de elaboración de dichos aggeres; cfr. igualmente Chic, 1997a, 68 y n. 223).

En lo que atañe al río Duero y las cuestiones relativas a su navegación en época romana, encontraremos unas interesantes noticias en el texto de Apiano, quien sostiene la navegabilidad de este curso fluvial, junto a la de otros ríos peninsulares ibéricos como el sureño Baetis o el noroccidental Lethes/Letheo -el ya mencionado Limia, el río "del Olvido" de Estrabón, Geografía, III.3.5 (Apiano, Iber., 73 -dato recogido ya por García Bellido, art. cit., pp. 516-ss.); es igualmente Apiano quien brinda la referencia al abastecimiento del oppidum indígena de Numancia mediante el empleo de esquifes movidos a remos (sin descartar el uso de las velas) en el contexto del curso alto del Duero du- rante el prolongado sitio de la referida ciudad de la Meseta por las armas romanas en el siglo II a.C. (Iber., 91).

De acuerdo con el amasiense Estrabón, el Durius (nombre latino del Duero) contaría con un total de unos 800 estadios navegables (aproximadamente unos 150 kilómetros) desde su desembocadura hacia el interior; el primer puente fijo (un posible -pero como ya hemos visto, no obligadamente absoluto- límite para la navegación) sobre este río a la altura de la ciudad indígena de Acontia (o Akóntia/Akoútia), “...perteneciente a los vacceos”, según recoge el texto del geógrafo de Amasia; la mención del puente de Acontia en Estrabón (Geog., III.3.2); para la navegabilidad del Duero hasta casi el límite fronterizo entre los modernos estados de Portugal y España, puede contrastarse lo señalado asimismo por el propio Estrabón (III.3.4); para Akoútia, vid. la traducción y comentario de Estrabón por M ${ }^{\mathrm{a}}$.J. Meana y F. Piñero (1992, pg. 78, n. 140); estos investigadores aportan el nombre de Akoýtia/Akoútia frente a la Akóntia de la versión de A. Schulten (1963, pg. 79); de esta forma, el límite señalado por el antedicho Estrabón para la navegación por el Duero habría de encontrarse a la altura de Barca d'Alva (en la frontera entre España y Portugal, donde no casualmente encontraríamos de nuevo un topónimo referido a una barca -ila de cruce?), como recoge A. Schulten; esta cita de las potencialidades de navegación del Durius la hallamos solamente en el amasiense, siendo varias las fuentes que mencionan al Duero antiguo (Schulten, op. cit., pp. 76-ss.), aunque sin detenerse en las condiciones que dicho curso fluvial peninsular podía ofrecer con vistas a servir como medio de comunicación en época antigua; en este sentido, Pomponio Mela hace mención de este río en su Chorographia (III.9-10) y Plinio el Viejo hace lo propio en su Historia Natural (IV.112-113, 115); nuevamente Estrabón, por su parte, proporciona asimismo una interesante información relativa al carácter aurífero de los ríos lusitanos, entre los que señala especialmente al Duero; es también el amasiense -o casi- el único tratadista de la Antigüedad que se detiene a estudiar (con mayor o menor profundidad) las condiciones de navegabilidad of recidas por los cursos fluviales de la Lusitania (esto es, del Occidente peninsular ibérico), entre los que cita como susceptibles de sustentar la navegación (en mayor o menor escala) a los ríos Mundas, Vacua, Durius, Tagus, Limia/Oblivionis y Minius/Benis (Estr., III.3.4). 
La amplia desembocadura del río Durius-Duero habría contado con dos núcleos de población entre los cuales discurría el río, unos núcleos que Schulten identifica con el enclave indígena de Cale (hoy día Villanova de Gaia), en la ribera meridional del Durius, de una parte, y con el núcleo romano de Portum (la moderna ciudad de Porto, el "puerto" de la desembocadura y estuario del Durius, relevante enclave humano cuyo mismo nombre muestra su naturaleza y su función principal, motivo y causa de su misma existencia: el "puerto"), en la orilla septentrional, de otra (con esta combinación se completaría el dualismo entre ciudad indígena y ciudad latina que en otros casos y lugares encontramos fundidas en un mismo núcleo; a partir de estos asentamientos poblacionales (esto es, de la combinación de Portum y Cale) se habría originado el nombre del actual Portugal (sobre la desembocadura del Durius, Ptolomeo, II.5.1; igualmente, Corp Gloss. V. 191. 36, donde se especifica que el Duero "...infundit in Oceano occidentali inter duos oppidos...”; cfr. Schulten, op. cit., pg. 79; para los afluentes del Duero que aparecen mencionados por una u otra fuente literaria de la Antigüedad nos remitimos a Schulten, op. cit., pp. 80-84).

La información que ofrece Estrabón (a las que hemos hecho referencia con anterioridad) acerca de las crecidas del río Tajo se ve confirmada por los datos de las condiciones modernas de los cursos fluviales de la vertiente atlántica peninsular; así, el Duero alcanza unos niveles que llegan a superar en treinta veces su módulo, mientras el Guadiana cuenta con una cifra que oscila en 10 y 70 veces de diferencia entre el caudal máximo de las medias diarias y el caudal máximo instantáneo en las crecidas; en lo que respecta al río Tajo, sus crecidas pueden alcanzar una cifra 37 veces superior a su módulo, y los caudales máximos pueden oscilar entre cifras 20 y 45 veces mayores que el módulo. Son, de todos modos, cifras que se encuentran lejos de las aportadas por los ríos de la vertiente mediterránea, como el Turia o el Mijares, que pueden aumentar su caudal de 237 a 420 veces su media, o el Segura, que puede contar con máximos instantáneos de $971 \mathrm{~m}^{3} / \mathrm{s}$. y con crecidas -más modestas, empero, que el Turia y el Mijares- que llegan a superar en 68 veces su módulo; vid. V. Bielza de Ory (1989, pp. 290-ss.).

Por lo que se refiere a los valores del caudal medio de estos ríos de la vertiente atlántica, el Duero presenta en Villamarciel, al Sur de su confluencia con el Adaja y el Pisuerga, un caudal medio de 143'1 $\mathrm{m}^{3} / \mathrm{s}$., mientras por su parte el Tajo presenta en Alcántara $30111 \mathrm{~m}^{3} / \mathrm{s}$. de caudal medio, unos valores que -por sí mismos- parecen hablar a favor de las hipotéticas condiciones (favorables) de dichos cursos de cara a su navegabilidad.

En líneas generales, cabe señalar que los ríos de la vertiente atlántica penisular se caracterizan por la escasa pendiente que deben salvar, por la longitud de sus cursos y por disfrutar de un elevado caudal. Todos éstos son factores que debían influir de modo favorable en las condiciones y las posibilidades de navegabilidad de los cauces fluviales, puesto que al tiempo que proporcionan (como se ha visto) unos elevados caudales medios, ayudan a proporcionar estabilidad a sus cursos, de manera que queden relativamente neutralizados los contrastes (que son consecuencia de las condiciones climatológicas y físicas), de forma que las cuencas más pequeñas, como pueden ser las mediterráneas, son las que sufren unos desequilibrios (con consecuencias como las crecidas) más marcados (por el volumen de agua desaguado en relación con la superficie de la cuenca, lo que puede tener como consecuencia -y como agravante del fenómeno- la rapidez y violencia del suceso), mientras las cuencas más amplias gozan de una mayor capacidad para encajar y absorber hipotéticas crecidas -y soportar, en el caso opuesto, los estiajes (Sala: 1989, pp. 261-ss.).

Bibliografía

A.A.V.V. (1980), Obras Públicas en la Hispania Romana, Madrid.

Álvarez Martínez, J.Mª . (1983), El puente romano de Mérida, Monografías Emeritenses 1, Badajoz.

Álvarez Martínez, J.Ma․ (2005), "Puentes de la Vía de la Plata y de sus inmediaciones”, Anas,18, 123-151.

Alves, F.J.S. (1986), “A piroga monóxila de Geraz do Lima”, O Arqueólogo Português. IV, 4, 209-234.

Bendala Galán, M. (1986-1987), “Ab ostio fluminis Anae...", Cuadernos de Prehistoria y Arqueología de la Universidad Autónoma de Madrid (CuPAUAM), 13-14, 129-139.

Bielza de Ory, V. (coord.) (1989), Territorio y Sociedad en España, I. Geografía Física. Madrid.

Bonsor, G.E. (1989), Expedición arqueológica a lo largo del Guadalquivir, Écija.

Briant, P. (1986), Alexandre et les 'katarraktes' 
du Tigre. Mélanges M. Labrousse, Toulouse.

Cerrillo Martín de Cáceres, E. (1995), "Los últimos romanos en Lusitania. Entre la tradición y el cambio", Los últimos romanos en Lusitania, Cuadernos Emeritenses, 10, Mérida, 11-48.

Chic García, G. (1979), "Gades y la desembocadura del Guadalquivir”, Gades, 3, 7-23.

(1990), La Navegación por el Guadalquivir entre Córdoba y Sevilla en época romana, Écija.

(1992), "El conjunto alfarero romano de La Catria. Una reconsideración”, Minius, 1, 07-136.

(1993), "La Navegación fluvial en época romana", Revista de Arqueología, 142, 28-39.

(1997a), Historia Económica de la Bética en la época de Augusto, Sevilla.

(1997b), El mito de la mujer, el horno, el hombre y el viento. Sobre el sentido de las palabras "fornicar" y "follar", Sevilla.

Eckoldt, M. (1984), "Navigation on small rivers in Central Europe in Roman and Medieval times", International Journal of Nautical Archaeo$\log y, 13.1,3-10$.

Forbes, R.J. (1965), Studies in Ancient Technology (II), Leiden.

García, J.C. (1982), Navegabilidade e Navegaçâo no Baixo Guadiana, Lisboa.

(1996), A Navegaçâo no Baixo Guadiana durante o ciclo do Minério (1857-1917 (I), Porto.

García Bellido, A. (1944), "La Navegación Ibérica en la Antigüedad. Según los textos clásicos y la arqueología”, Estudios Geográficos, 16, 511560.

Grénier, A. (1960), Manuel d'Archéologie GalloRomain, París.

Kalb, P. y Höck, M. (1988), “Moron”, Conimbriga, 27, 189-201.

Mateos Cruz, P. (1995), "Arqueología de la Tardoantigüedad en Mérida: estado de la cuestión”, Los últimos romanos en Lusitania, Cuadernos Emeritenses, 10, Mérida, 25-152.

Meana, Mª .J. y Piñero, F. (1992), Estrabón. Geografía. Libros III-IV, Biblioteca Clásica Gredos, 169, Madrid.

Millán León, J. (1989), Ilipa Magna, Écija.

Do Paço, A. y Bação Leal, J. (1968), "Castelo de Lousa (Mourão). Campanhas de excavações de 1965, 1966 e 1967", Conimbriga, 7, 1-7.

Parodi Álvarez, M.J. (2000), “Algunas notas sobre el papel de lagos y lagunas costeras peninsulares como soportes para la navegación en época altoimperial”, Spal, 8, 207-216.
(2001), Rios y lagunas de Hispania como vías de comunicación. La Navegación interior en la Hispania romana, Écija.

(2003), El Baetis-Guadalquivir, Puerta de Hispania, Monografías Sanluqueñas I, Fundación Municipal de Cultura, Sanlúcar de Barrameda.

(2003a), "Notas sobre el Guadalquivir altoimperial como vía de comercio. Reflexiones sobre la Economía del río", Actas del $3^{\circ}$ Congreso de Historia de Andalucía, 4. Historia Antigua, Córdoba, 531-543.

(2003b), "Notas sobre la economía del Anas: apuntes sobre su navegación antigua", Puertos fluviales antiguos: Ciudad, desarrollo e infraestructuras, Actas IV Jornadas de Arqueología Subacuática (Pascual Berlanga, G. y Pérez Ballester, J., Eds.), Valencia, 49-58.

(2003c), "El papel económico de los cursos acuáticos como vías de comunicación en la Hispania romana. Algunas notas", Actas de los XVII Encuentros de Historia y Arqueología de San Fernando, San Fernando, 295-315.

(2004), "De fríos, calores, vientos, espacios vacíos y espacios llenos. Reflexiones acerca del libro $E l$ Mito de la Mujer, el Horno, el Hombre y el Viento. Sobre el sentido de las palabras Fornicar \& Follar. Padilla Libros Editores \& Libreros, Sevilla 1997, de G. Chic García”, Revista Atlántica y Mediterránea de Prehistoria y Arqueología Social, V, 357-367.

(2007), “Aprovechando que el Baetis pasa por Ili$p a$. Reflexiones sobre la navegación fluvial en la Península Ibérica como agente económico en época altoimperial romana", Ilipa Antiqua. De la Prehistoria a la Época Romana, Actas del I Congreso de Historia de Alcalá del Río, Sevilla, 255-266.

(2008), "Sobre "pateras" romanas. Embarcaciones ligeras en un contexto meridional hispano y potencialidades de uso", Comercio, redistribución y fondeaderos. La navegación a vela en el Mediterráneo, Actas de las V Jornadas Internacionales de Arqueología Subacuática, Valencia, 435-450.

Ponsich, M. (1979), Implantation rurale antique sur la Bas-Guadalquivir, París.

Rodríguez Díaz, A. (1994), "El valle medio del Guadiana, 'Espacio de Frontera' en la Protohistoria del Suroeste (I)”, Saguntum, 27, 107-124.

(1995), "El valle medio del Guadiana, 'Espacio de Frontera' en la Protohistoria del Suroeste (II)”, 
Saguntum, 28, 111-130.

Rougé, J. (1966), Recherches sur l'organisation du commerce maritime en Mediterranée sous l'Empire Romain, París.

Sala, M. (1989): "Las aguas continentales”, Territorio y Sociedad en España, I. Geografía Física. (Bielza de Ory, V., Ed.), Madrid, 261-275.

Schulten, A. (1963), Geografía y Etnografía Antiguas de la Península Ibérica (II), Madrid.

Da Silva Lopes, J.B. (1841, reed. en Faro, 1988), Corografia ou Memória Económica, Estatística e Topográfica do Reino do Algarve (I), Lisboa/Faro, 23.

Spaar, S.L. (1981), The Ports of Roman Baetica, Ann Arbor-Michigan. 
